\title{
Optimization of the PAXgene ${ }^{\mathrm{TM}}$ Blood RNA Extraction System for Gene Expression Analysis of Clinical Samples
}

\author{
Viengthong Chai, Aikaterini Vassilakos, Yoon Lee, ${ }^{*}$ Jim A. Wright, and Aiping H. Young
}

Lorus Therapeutics Inc., Toronto, Canada

\begin{abstract}
One major problem associated with collecting whole blood from patients for use as a source of RNA in gene expression studies is that the RNA degrades during collection and storage. Preservation of RNA quality is vital in such studies because the stability of the RNA ultimately affects analysis of gene expression. In this study the PAXgene ${ }^{\mathrm{TM}}$ blood collection system was compared with a standard erythrocyte lysis method for isolating RNA from blood samples. The methods were compared in terms of RNA yield, RNA stabilization, and DNA contamination. The study also included the downstream application to RTPCR analysis for relative mRNA expression levels of the ribonucleotide reductase subunits $R 1$ and R2. The results show that blood collection in conventional collection tubes, and leukocyte isolation by

erythrocyte lysis lead to significant degradation of RNA. Our findings confirm the ability of PAXgene ${ }^{T M}$ to stabilize RNA in whole blood; however, RNA extracted by the PAXgene ${ }^{T M}$ method contained significant DNA contamination. Given the low basal expression of the target genes analyzed in this study, contaminating DNA could potentially affect accurate interpretation of RT-PCR data. As a result, the PAXgene ${ }^{T M}$ protocol was optimized to include off-column DNase treatments, which yielded high-quality RNA suitable for gene expression studies. Furthermore, the results suggest that RNA isolation with PAXgene $\mathrm{TM}^{\mathrm{T}}$ is advantageous compared to traditional extraction methods for RT-PCR analysis of large or different-sized amplicons. J. Clin. Lab. Anal. 19:182-188, 2005. (c) 2005 Wiley-Liss, Inc.
\end{abstract} DNase; column

\section{INTRODUCTION}

A limitation of studies that use human whole blood as a source of RNA for gene expression studies is that the RNA degrades during collection and subsequent sample storage (1-3). Current methods for extracting RNA from whole blood require immediate sample processing to minimize degradation of the RNA. These procedures are often impractical in a clinical setting, and typical processing times result in low-quality RNA. PreAnalytiX (Hombrechtikon, Switzerland) has developed a novel blood collection system, called the PAXgene ${ }^{\mathrm{TM}}$ blood RNA system, in which RNA is stabilized during phlebotomy and sample storage. In this study RNA extracted using the PAXgene ${ }^{\mathrm{TM}}$ system was compared to RNA isolated from whole blood using a standard leukocyte isolation method. RNA yield, integrity, and stability, and the results from a downstream gene expression analysis were compared. In addition, the PAXgene ${ }^{\mathrm{TM}}$ protocol was modified so that DNA is completely removed, resulting in improved RNA quality. The results demonstrate that the PAXgene ${ }^{\mathrm{TM}}$ system can stabilize RNA for up to 5 days at room temperature, with little change in the relative mRNA expression levels of the target genes ribonucleotide reductase R1 and R2 subunits.

\section{MATERIALS AND METHODS}

After our institutional review board approved the study, and written informed consent was obtained from the subjects, whole blood was drawn from three volunteers in accordance with the International Conference on Harmonization's Guidelines for Good Clinical Practices, as follows: 1) $5 \mathrm{~mL}$ of blood were

Abbreviations: R2, ribonucleotide reductase subunit 2; R1, ribonucleotide reductase subunit 1 .

*Correspondence to: Yoon Lee, Lorus Therapeutics Inc., 2 Meridian Road, Toronto, ON, Canada, M9W 4Z7.

E-mail: ylee@lorusthera.com

Received 15 October 2004; Accepted 5 April 2005

DOI $10.1002 /$ jcla. 20075

Published online in Wiley InterScience (www.interscience.wiley.com). 
collected into two 4-mL Vacutainer ${ }^{\circledR}$ Plus K2 EDTA tubes (Becton Dickinson, Franklin Lakes, NJ) for leukocyte isolation by erythrocyte lysis and RNA extraction; 2) $5 \mathrm{~mL}$ of blood were collected directly into two 2.5-mL PAXgene ${ }^{\mathrm{TM}}$ blood RNA tubes (Qiagen, Mississauga, Canada) and stored at room temperature for $24 \mathrm{hr}$ before processing; and 3) $5 \mathrm{~mL}$ of blood were collected directly into two $2.5-\mathrm{mL}$ PAXgene ${ }^{\mathrm{TM}}$ blood RNA tubes and stored at room temperature for 5 days before processing.

To simulate conditions under which samples are routinely processed in clinics, the blood collected in the Vacutainer ${ }^{\circledR}$ Plus tubes for erythrocyte lysis was incubated at room temperature for $3 \mathrm{hr}$ before processing. Erythrocytes were then selectively lysed by the addition of a hypotonic buffer. Briefly, $5 \mathrm{~mL}$ of blood were mixed with $25 \mathrm{~mL}$ of erythrocyte lysis buffer (150 $\mathrm{mM}$ ammonium chloride, $10 \mathrm{mM}$ potassium bicarbonate, and $1 \mathrm{mM}$ EDTA disodium salt) and incubated on ice for $15 \mathrm{~min}$, vortexing twice during the incubation. The samples were centrifuged at $500 \times g$ for $10 \mathrm{~min}$ at $4^{\circ} \mathrm{C}$ and the supernatant was discarded. Then $1 \mathrm{~mL}$ of lysis buffer was added to the pellet and the leukocytes were resuspended by vortexing. The leukocyte suspension was centrifuged, the supernatant was removed, and the leukocyte pellet was immediately frozen in a dry ice/ethanol mixture and stored at $-80^{\circ} \mathrm{C}$ for 6 days. Total cellular RNA was extracted from the frozen leukocytes by means of TRIzol ${ }^{\circledR}$ Reagent (Invitrogen, Burlington, Canada) extraction according to the manufacturer's protocol. The RNA pellet was dissolved in $50 \mu \mathrm{L}$ of $\mathrm{DEPC}-\mathrm{H}_{2} \mathrm{O}$, heated at $95^{\circ} \mathrm{C}$ for $3 \mathrm{~min}$, and chilled on ice. The samples were then treated for $1 \mathrm{hr}$ at $37^{\circ} \mathrm{C}$ with DNase I using a DNase-free ${ }^{\mathrm{TM}}$ kit (Ambion Inc., Austin, TX), followed by the addition of DNase inactivation reagent. DNase I treatment was repeated to ensure complete removal of the DNA.

For blood samples collected directly into PAXgene $\mathrm{T}^{\mathrm{TM}}$ blood RNA tubes, total cellular RNA was extracted from the samples with the PAXgene ${ }^{\mathrm{TM}}$ blood RNA kit (Qiagen, Mississauga, Canada) according to the manufacturer's protocol, $24 \mathrm{hr}$ or 5 days after phlebotomy, and subjected to an on-column DNase I treatment with the use of an RNase-free DNase set (Qiagen, Mississauga, Canada).

The concentration of RNA was determined by spectrophotometric analysis of the absorbance of each sample at $260 \mathrm{~nm}$. The RNA yield is expressed as total RNA per $5 \mathrm{~mL}$ whole blood. The integrity of the RNA samples was assessed by denaturing-gel electrophoresis with a $1.2 \%$ formaldehyde-agarose gel, as described in Appendix E of the PAXgene ${ }^{\mathrm{TM}}$ blood RNA kit handbook. The gel was washed three times in DEPC- $\mathrm{H}_{2} \mathrm{O}$ for 15 min, and the RNA was transferred onto a Nytran
SuPerCharge nylon membrane (Schleicher \& Schuell, Keene, NH) by capillary transfer in $20 \times$ SSC overnight. The membrane was air-dried and the RNA was cross-linked to the membrane by exposure to UV light (FB-UVXL-1000; Fisher Scientific, Canada). The 28S and $18 \mathrm{~S}$ ribosomal RNA (rRNA) species were visualized by methylene blue staining $(0.04 \%$ methylene blue in $0.5 \mathrm{M}$ sodium acetate, $\mathrm{pH}$ 5.2) of the membrane followed by several washes with deionized water. The stained membrane was photographed with the use of a Gel Doc 2000 gel documentation system (BIO-RAD, Hercules, CA).

To assess the effect of the three blood-collection methods on gene expression, the isolated RNA samples were subjected to RT-PCR analysis to determine ribonucleotide reductase subunits R1 and R2, and $\beta$-actin expression levels. RT-PCR analyses were performed using master mixes to ensure that reverse transcription of RNA and PCR amplification of cDNAs were carried out under identical conditions. RNA was reverse-transcribed by incubation with $2.5 \mathrm{ng} / \mu \mathrm{L}$ random hexanucleotide primer (Amersham Pharmacia, Piscataway, NJ), $50 \mathrm{mM}$ Tris- $\mathrm{HCl}, 75 \mathrm{mM} \mathrm{KCl}$, $3 \mathrm{mM} \mathrm{MgCl} 2,10 \mathrm{mM}$ DTT, $128 \mathrm{U}$ of RNAguard (Amersham Pharmacia), $0.5 \mathrm{mM}$ each dNTP (Amersham Pharmacia), and $10 \mathrm{U} / \mu \mathrm{L}$ of Moloney murine leukemia virus reverse transcriptase (Invitrogen, Burlington, Canada) according to the instructions from Invitrogen. Negative control reactions for the reverse transcription included a sample containing RNA but no reverse transcriptase, and a sample containing DEPCtreated $\mathrm{H}_{2} \mathrm{O}$ in place of the RNA. Following reverse transcription all samples were treated with RNase $\mathrm{H}$ (Amersham Pharmacia) at $37^{\circ} \mathrm{C}$ for $20 \mathrm{~min}$.

Amplification was performed in $25 \mu \mathrm{L}$ reaction mixtures containing cDNA derived from $50 \mathrm{ng}$ of RNA, $10 \mathrm{mM}$ Tris, $50 \mathrm{mM} \mathrm{KCl}, 1.5 \mathrm{mM} \mathrm{MgCl}_{2}$, $0.2 \mathrm{mM}$ each dNTP, $0.45 \mu \mathrm{M}$ each R1, R2, or $\beta$-actin $5^{\prime}$ and $3^{\prime}$ primers (Invitrogen, Burlington, Canada), and $1.25 \mathrm{U}$ of Taq polymerase (Amersham Pharmacia, Piscataway, NJ). PCR primers were designed to span at least one intron of the gene transcript. As a negative control for the PCR reaction, DEPC- $\mathrm{H}_{2} \mathrm{O}$ was used in place of cDNA. The PCR samples were overlaid with mineral oil and placed in a Biometra ${ }^{\circledR}$ Tpersonal DNA thermal cycler (Montreal Biotech Inc., Kirkland, Canada). The samples were heated to $94^{\circ} \mathrm{C}$ for $4 \mathrm{~min}$ and subjected to cycles of $94^{\circ} \mathrm{C}$ for $30 \mathrm{sec}, 58^{\circ} \mathrm{C}$ for 30 sec, and $72^{\circ} \mathrm{C}$ for $1 \mathrm{~min}$. The PCR samples were subjected to electrophoresis in $6 \%$ polyacrylamide gels at $100 \mathrm{~V}$ for $50 \mathrm{~min}$ and stained with SYBR Green I ${ }^{\mathrm{TM}}$ (Molecular Probes, Eugene, OR) for $15 \mathrm{~min}$. The gels were exposed to UV light using a BIO-RAD Gel Doc 2000 gel documentation system, and quantification of 
PCR products was performed using Quantity One analysis software (BIO-RAD, Hercules, CA).

\section{RESULTS AND DISCUSSION}

\section{RNA Concentration and Yield}

Although the concentration of RNA isolated via the PAXgene ${ }^{\mathrm{TM}}$ method was lower than that obtained with the standard method (not shown), there was no

TABLE 1. Total yield of RNA samples $(\mu \mathrm{g}$ RNA/5 mL whole blood) extracted via the erythrocyte lysis/TRIzol method or PAXgene method

\begin{tabular}{|c|c|c|c|}
\hline & Volunteer \#1 & Volunteer \#2 & Volunteer \#3 \\
\hline Lysis/TRIzol method & 11.7 & 6.6 & 12.1 \\
\hline PAXgene $(24 \mathrm{~h})^{\mathrm{a}}$ & 14.3 & 9.7 & 21.9 \\
\hline PAXgene (5 days) ${ }^{\mathrm{a}}$ & 9.7 & 8.8 & 11.2 \\
\hline
\end{tabular}

${ }^{\mathrm{a}}$ Blood was directly collected into PAXgene ${ }^{\mathrm{TM}}$ Blood RNA tubes and stored at room temperature for $24 \mathrm{~h}$ or 5 days as indicated. significant difference in total RNA yield (Table 1). RNA yield was highest in blood samples that were collected in PAXgene ${ }^{\mathrm{TM}}$ tubes and processed $24 \mathrm{hr}$ thereafter.

\section{RNA Integrity}

To assess RNA integrity, RNA samples were resolved on denaturing agarose gels for visualization of the $28 \mathrm{~S}$ and $18 \mathrm{~S}$ rRNAs. There was extensive RNA degradation in the samples extracted via the standard method, as indicated by the lack of intact $28 \mathrm{~S}$ and $18 \mathrm{~S}$ rRNAs (Fig. 1). Smaller RNA fragments $(\sim 0.2-2 \mathrm{~kb})$ were clearly visible in these samples. Degradation likely occurred between the time that the blood sample was drawn and the leukocytes were isolated.

$28 \mathrm{~S}$ and $18 \mathrm{~S}$ rRNAs were intact in RNA samples isolated via the PAXgene ${ }^{\mathrm{TM}}$ method both $24 \mathrm{hr}$ and 5 days after blood collection (Fig. 1). In addition, there were no small RNA fragments present, indicating that RNA integrity was preserved by PAXgene ${ }^{\mathrm{TM}}$. Although

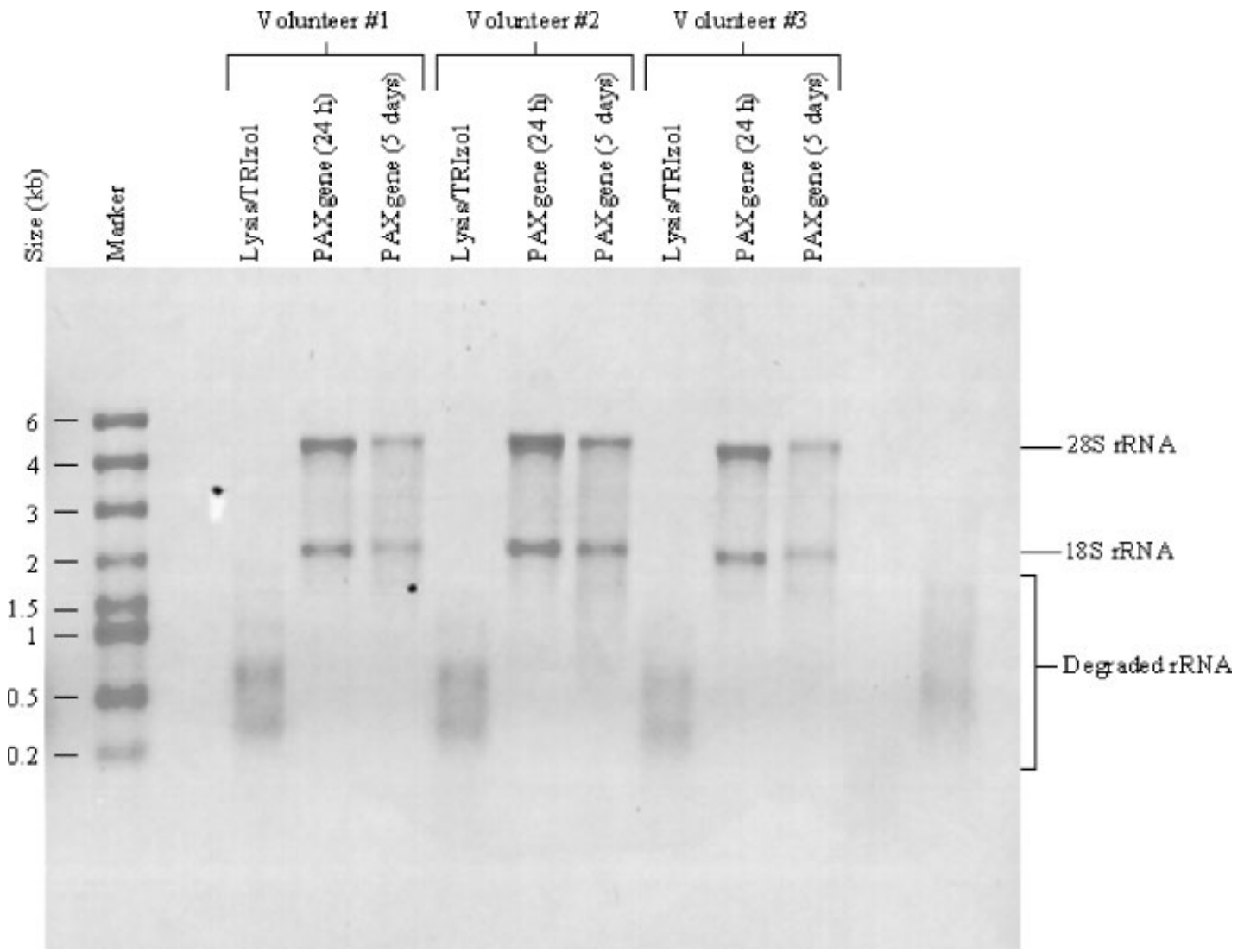

Fig. 1. Integrity of RNA samples isolated via the standard erythrocyte lysis/TRIzol method or the PAXgene ${ }^{\mathrm{TM}}$ method. Leukocyte RNA from three volunteers was extracted using the lysis/TRIzol method or PAXgene ${ }^{\mathrm{TM}}$ system as described in Materials and Methods. Degradation was observed in each RNA sample that was isolated via the lysis/TRIzol method, whereas 28S and 18S rRNA species remained intact in samples isolated $24 \mathrm{hr}$ or 5 days after blood collection using the PAXgene ${ }^{\mathrm{TM}}$ blood RNA kit. 
an equivalent amount of total RNA $(1 \mu \mathrm{g})$ from each sample was loaded per lane, the level of intact $28 \mathrm{~S}$ and $18 \mathrm{~S}$ rRNAs was lower in samples stored for 5 days than in those that were processed $24 \mathrm{hr}$ after blood collection, suggesting that some degradation may occur with time. PAXgene ${ }^{\mathrm{TM}}$ appears to stabilize RNA and prevent degradation even when blood is kept at room temperature for up to 5 days.

\section{DNA Contamination in Extracted RNA Samples}

Prior to detailed RT-PCR analyses of R1, R2, and $\beta$-actin gene expression, preliminary RT-PCR analyses were performed at 38,40 , and 30 cycles of amplification, respectively, to determine whether there were contaminating DNA sequences in the RNA samples. RNA samples isolated by erythrocyte lysis/TRIzol extraction followed by two rounds of DNase I treatment with Ambion's DNase-free ${ }^{\mathrm{TM}}$ kit were free of DNA contamination, in that there were no PCR products in control reactions that contained RNA but no reverse transcriptase (-RT) (Fig. 2). In contrast, PCR products that were similar in size to R 2 and $\beta$-actin were observed in -RT control samples from all RNA samples isolated via the PAXgene ${ }^{\mathrm{TM}}$ method (Fig. 2), which suggests that the on-column DNase I digestion is insufficient for removing small quantities of DNA. PCR products were absent in control reactions for the reverse transcription and PCR (-RNA and-cDNA samples), indicating that the RT-PCR reagents were free of contamination. Thus, the source of the PCR products observed in the $-\mathrm{RT}$ controls of RNA samples isolated via the PAXgene ${ }^{\mathrm{TM}}$ system was the RNA extracts. These results are consistent with those of other reports (4-7) and
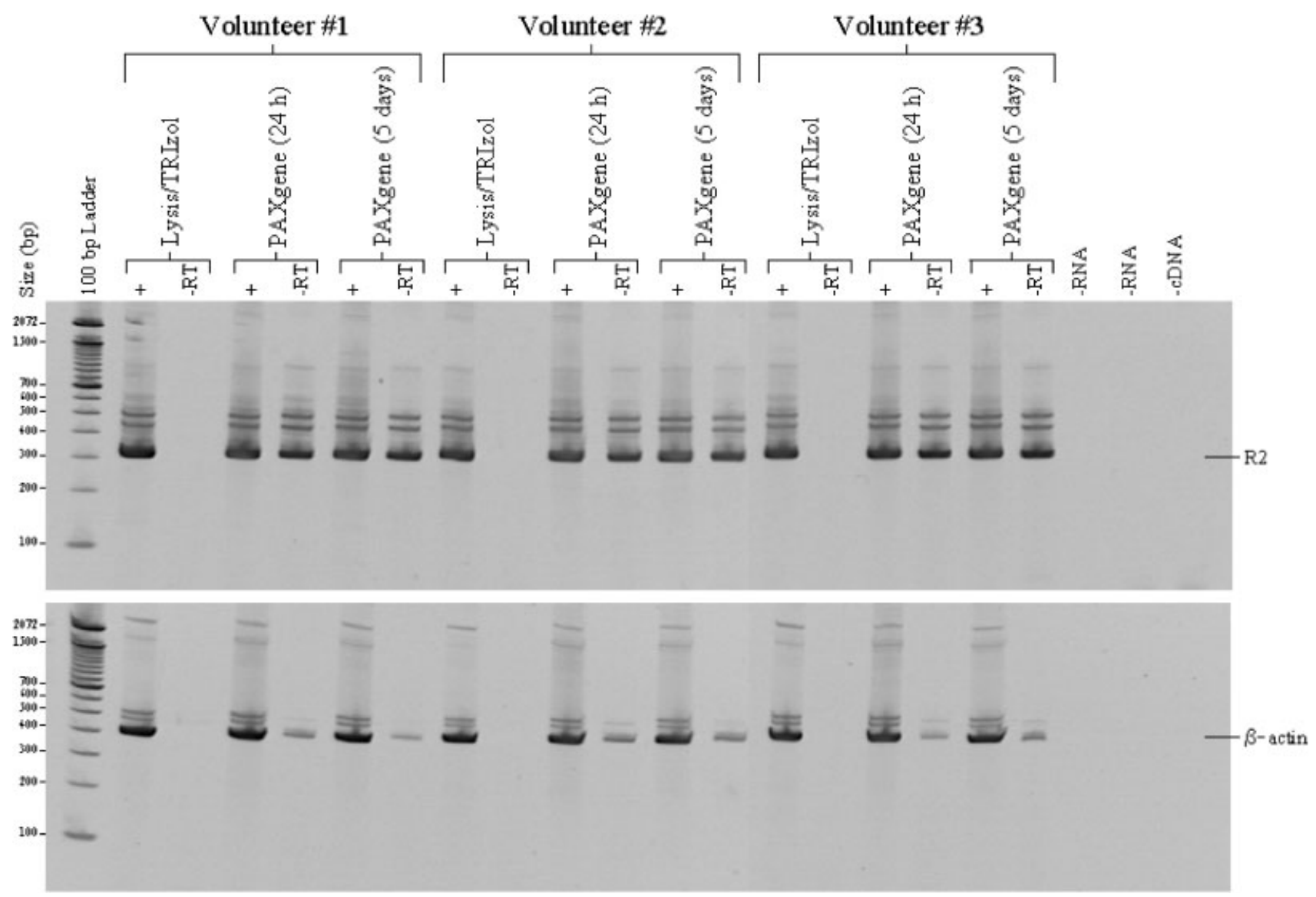

Fig. 2. R2 and $\beta$-actin DNA contamination in RNA samples isolated via the PAXgene ${ }^{\mathrm{TM}}$ method. Leukocyte RNA from three volunteers, isolated via the lysis/TRIzol method or the PAXgene ${ }^{\mathrm{TM}}$ method, was reverse-transcribed to cDNA in the presence $(+)$ or absence $(-\mathrm{RT})$ of reverse transcriptase for PCR amplification of R2 (307 bp amplicon, top panel) and $\beta$-actin ( $410 \mathrm{bp}$ amplicon, bottom panel). As indicated by the absence of PCR products in the corresponding - RT samples, DNase treatments of RNA using Ambion's DNA-free ${ }^{\text {TM }}$ kit removed all DNA contaminants in samples isolated via the lysis/TRIzol method. Contaminating bands were observed in all -RT controls for PAXgene ${ }^{\text {TM }}$ samples that were treated on-column with DNase according to the manufacturer's instructions, which suggests that the PAXgene ${ }^{\mathrm{TM}}$ RNA samples contained contaminating DNA sequences. The reverse transcription and PCR reagents were free of DNA contaminants, as shown by the lack of PCR products in samples that were reverse-transcribed in the absence of RNA (-RNA) or amplified without DNA template (-cDNA). 
emphasize the importance of completely removing residual DNA from the RNA extracts prior to gene expression analysis by PCR or real-time PCR, and including negative control samples in which reverse transcription is performed in the absence of reverse transcriptase. A previous study by Thach et al. (8) suggested that low levels of DNA contamination with the on-column method may not be a matter of concern; however, in gene expression studies in which the target gene is expressed at low levels it is essential to remove DNA prior to amplification. The exact source of the observed contaminating DNA species in the present study is currently not known.
RNA samples isolated via PAXgene ${ }^{\mathrm{TM}}$ were retreated with DNase I using the DNase-free ${ }^{\mathrm{TM}}$ kit from Ambion, and subsequently analyzed for DNA contamination by RT-PCR. As shown in Fig. 3, a second DNase I treatment was effective at removing contaminating DNA without affecting R1, R2, or $\beta$-actin amplification.

\section{R1, R2, and $\beta$-Actin Gene Expression in Extracted RNA Samples}

PCR amplification of R1, R2, and $\beta$-actin was performed for 31,32 , and 21 cycles, respectively. These
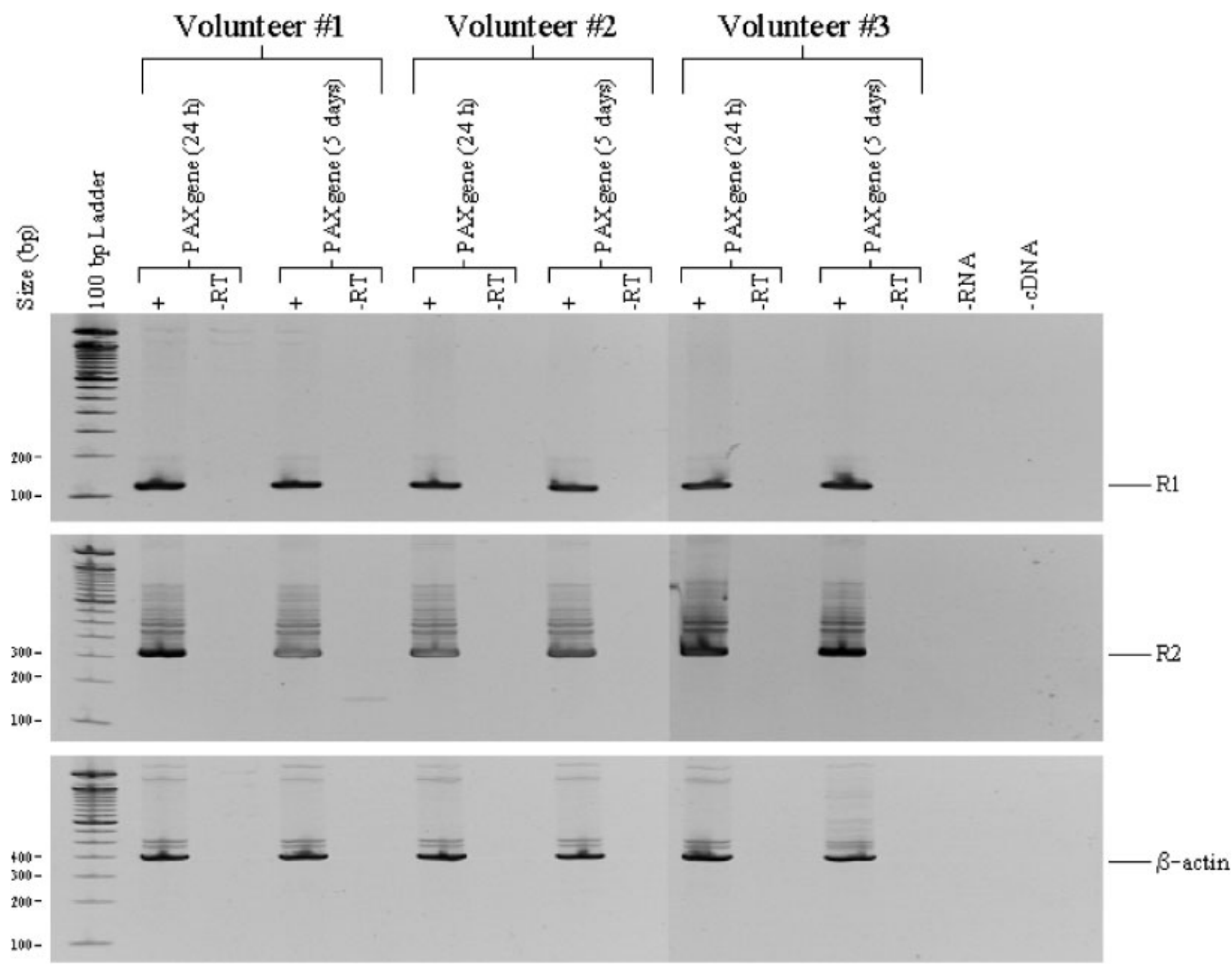

Fig. 3. Amplification of R1, R2, and $\beta$-actin in PAXgene ${ }^{\mathrm{TM}}$ RNA samples after retreatment with DNase I. PAXgene ${ }^{\mathrm{TM}}$ RNA samples that were treated on-column with DNase I (Qiagen, Mississauga, Canada) and previously shown to contain DNA contaminants (Fig. 2) were retreated with DNase I using Ambion's DNase-free ${ }^{\mathrm{TM}}$ kit. The RNA samples were reverse-transcribed to cDNA in the presence $(+)$ or absence $(-\mathrm{RT})$ of reverse transcriptase for PCR amplification of R1 (112 bp amplicon, top panel), R2 (307 bp amplicon, center panel), and $\beta$-actin (410 bp amplicon, bottom panel). Contaminating bands were not observed in any of the -RT samples, indicating that the second DNase treatment using the DNase-free ${ }^{\mathrm{TM}}$ kit was effective at removing contaminating DNA sequences from RNA samples isolated via the PAXgene ${ }^{\mathrm{TM}}$ blood RNA extraction method. 
cycle numbers were determined to be within the range of linear amplification for each gene using leukocyte RNA samples (not shown).

$\mathrm{R} 1$, R2, and $\beta$-actin PCR products were quantified and expressed relative to those in the RNA samples that were isolated via the standard method. R1, R2, and $\beta$-actin expression was the same or higher in samples extracted using the PAXgene ${ }^{\mathrm{TM}}$ system $24 \mathrm{hr}$ or 5 days after phlebotomy compared to samples extracted via the standard method (Table 2). In addition, expression was higher after $24 \mathrm{hr}$ than after 5 days in PAXgene ${ }^{\mathrm{TM}}$, consistent with a loss of total RNA (Fig. 1). Note that these data are not normalized to a control gene, and as such interpretation of the results may be complicated by variations in the reactions that may contribute to small differences in expression.

Normalization of R1 and R2 levels to that of the housekeeping $\beta$-actin gene in the same sample showed that both R1/actin and R2/actin levels were higher in samples that were extracted via the standard method compared to samples extracted via the PAXgene ${ }^{\mathrm{TM}}$ system (for $24 \mathrm{hr}$ or 5 days; Table 3 ). This finding is not surprising considering that $\beta$-actin expression in the PAXgene ${ }^{\mathrm{TM}}$ samples was higher than that in samples isolated via the standard method (Table 2). Given that the amplified region of $\beta$-actin is larger than the $\mathrm{R} 1$ and $\mathrm{R} 2$ regions, it is more susceptible to loss by degradation when it is extracted using the standard method compared to extraction via PAXgene ${ }^{\mathrm{TM}}$. Although there was a decrease in the individual R1, R2, and $\beta$-actin expression after blood was stored for 5 days in PAXgene ${ }^{\mathrm{TM}}$ (Table 2), normalization of R1 and R2 levels to that of the housekeeping $\beta$-actin gene showed that R1 and R2 levels in the 24-hr PAXgene ${ }^{\mathrm{TM}}$ samples were the same as those in the 5-day sample (Table 3). Thus, storage of blood in PAXgene ${ }^{\mathrm{TM}}$ for up to 5 days did not affect R1 or R2 expression when normalized to that of $\beta$-actin. This observation supports the manufacturer's claim that RNA is stabilized for several days at room temperature (9), and extends the results by demonstrating reproducible downstream application of the isolated RNA.

Despite the extent of RNA degradation observed in samples isolated via the standard method (Fig. 1), amplification of R1, R2, and $\beta$-actin was not affected to a greater extent than expected, which suggests that the amplified portion of the target RNA still remained intact in the extracted samples. This is likely a reflection of the small region that was amplified for each gene (112-410 bp). Taken together, these results suggest that the use of the PAXgene ${ }^{\mathrm{TM}}$ system is advantageous compared to the standard lysis/TRIzol method for analyzing larger sequences of RNA, or in situations where the target and control gene amplicons are of different sizes.

In summary, the total RNA yield from whole blood was not improved by the use of the PAXgene ${ }^{\mathrm{TM}}$ method of RNA extraction, but there was a clear

TABLE 2. Relative levels of R1, R2, and $\beta$-actin $\mathrm{mRNA}^{\mathrm{a}}$ in RNA samples extracted via the erythrocyte lysis/TRIzol method or PAXgene method

\begin{tabular}{|c|c|c|c|c|c|c|c|c|c|}
\hline & \multicolumn{3}{|c|}{ Volunteer \#1 } & \multicolumn{3}{|c|}{ Volunteer \#2 } & \multicolumn{3}{|c|}{ Volunteer \#3 } \\
\hline & $\mathrm{R} 1$ & R2 & Actin & $\mathrm{R} 1$ & R2 & Actin & R1 & R2 & Actin \\
\hline Lysis/TRIzol method & 1.0 & 1.0 & 1.0 & 1.0 & 1.0 & 1.0 & 1.0 & 1.0 & 1.0 \\
\hline PAXgene $(24 \mathrm{~h})^{\mathrm{b}}$ & 1.1 & 1.0 & 1.4 & 2.3 & 2.6 & 6.6 & 1.7 & 1.1 & 2.3 \\
\hline PAXgene $(5 \text { days })^{\mathrm{b}}$ & 0.97 & 0.85 & 1.1 & 1.9 & 2.2 & 5.8 & 1.3 & 0.94 & 1.7 \\
\hline
\end{tabular}

${ }^{a}$ mRNA levels are expressed relative to those in RNA samples extracted via the lysis/TRIzol method.

${ }^{\mathrm{b}}$ Blood was directly collected into PAXgene ${ }^{\mathrm{TM}}$ Blood RNA tubes and stored at room temperature for $24 \mathrm{~h}$ or 5 days as indicated.

TABLE 3. Normalized ratios of R1 and R2 gene expressiona in RNA samples extracted via the erythrocyte lysis/TRIzol method or PAXgene method

\begin{tabular}{|c|c|c|c|c|c|c|}
\hline & \multicolumn{2}{|c|}{ Volunteer \#1 } & \multicolumn{2}{|c|}{ Volunteer \#2 } & \multicolumn{2}{|c|}{ Volunteer \#3 } \\
\hline & $\mathrm{R} 1 /$ actin & $\mathrm{R} 2 /$ actin & $\mathrm{R} 1 /$ actin & $\mathrm{R} 2 /$ actin & $\mathrm{R} 1 /$ actin & R2/actin \\
\hline Lysis/TRIzol method & 1.3 & 1.8 & 2.6 & 2.7 & 1.5 & 2.4 \\
\hline PAXgene $(24 \mathrm{~h})^{\mathrm{b}}$ & 1.0 & 1.3 & 0.88 & 1.1 & 1.1 & 1.1 \\
\hline PAXgene $\left(5\right.$ days) ${ }^{\mathrm{b}}$ & 1.1 & 1.4 & 0.84 & 1.0 & 1.2 & 1.3 \\
\hline
\end{tabular}

${ }^{\mathrm{a}} \mathrm{R} 1$ and $\mathrm{R} 2$ gene expression is expressed as a ratio of the level of R1 or R2 mRNA over that of $\beta$-actin mRNA.

${ }^{\mathrm{b}}$ Blood was directly collected into PAXgene ${ }^{\mathrm{TM}}$ Blood RNA tubes and stored at room temperature for $24 \mathrm{~h}$ or 5 days as indicated. 
improvement in RNA integrity. When normalized to $\beta$-actin levels, R1 and R2 gene expression did not change in blood samples that were stored in PAXgene ${ }^{\mathrm{TM}}$ tubes for up to 5 days. This is an important feature in the clinical setting, where processing times may vary. In addition, extended storage at room temperature may have a significant impact on the cost of shipment to analytical facilities, which currently requires specialized dry ice containment. For applications such as RT-PCR or real-time PCR gene expression analyses, high-quality RNA is required because contaminating DNA sequences can skew the results and subsequent interpretation. A second DNase I treatment using Ambion's DNase-free ${ }^{\mathrm{TM}}$ kit was required for complete removal of DNA, which suggests that in PAXgene ${ }^{\mathrm{TM}}$ RNA isolations the on-column DNase digestion should be omitted and the RNA subjected to two rounds of DNase I treatment, off-column.

In conclusion, the PAXgene ${ }^{\mathrm{TM}}$ system simplifies the processing and storage of blood samples and improves the quality of the RNA, which may minimize variability among samples collected at different clinical sites within a single study. Together with a double off-column DNase digestion, high-quality RNA can be obtained for downstream applications.

\section{REFERENCES}

1. Freeman R, Wheeler J, Robertson H, Paes ML, Laidler J. In-vitro production of TNF-alpha in blood samples. Lancet 1990;336: 312-313.

2. Riches P, Gooding R, Millar BC, Rowbottom AW. Influence of collection and separation of blood samples on plasma IL-1, IL-6 and TNF-alpha concentrations. J Immunol Methods 1992;153:125-131.

3. Hartel C, Bein G, Muller-Steinhardt M, Kluter H. Ex vivo induction of cytokine mRNA expression in human blood samples. J Immunol Methods 2001;249:63-71.

4. Overbergh L, Valckx D, Waer M, Mathieu C. Quantification of murine cytokine mRNAs using real time quantitative reverse transcriptase PCR. Cytokine 1999;11:305-312.

5. Winer J, Jung CKS, Shackel I, Williams M. Development and validation of real-time quantitative reverse transcriptasepolymerase chain reaction for monitoring gene expression in cardiac myocytes in vitro. Anal Biochem 1999;270:41-49.

6. Aerts J, Wynendaele W, Paridaens R, et al. A real-time quantitative reverse transcriptase polymerase chain reaction (RT-PCR) to detect breast carcinoma cells in peripheral blood. Ann Oncol 2001;12:39-46.

7. Bustin SA. Quantification of mRNA using real-time reverse transcriptase PCR (RT-PCR): trends and problems. J Mol Endocrinol 2002;29:23-39.

8. Thach DC, Lin B, Walter E, et al. Assessment of two methods for handling blood in collection tubes with RNA stabilizing agent for surveillance of gene expression profiles with high density microarrays. J Immunol Methods 2003;283:269-279.

9. Rainen L, Oelmueller U, Jurgensen S, et al. Stabilization of mRNA expression in whole blood samples. Clin Chem 2002;48: 1883-1890. 